OPEN ACCESS

Edited by:

Zhiyong Gao,

Central South University, China

Reviewed by:

Sugata Chowdhury,

National Institute of Standards and Technology (NIST), United States

Shuai Wang,

Central South University, China

${ }^{*}$ Correspondence:

Chen Zhang

zc9303@126.com

Specialty section:

This article was submitted to Physical Chemistry and Chemical

Physics,

a section of the journa

Frontiers in Chemistry

Received: 13 July 2019 Accepted: 09 December 2019 Published: 24 December 2019

Citation:

Li L, Zhang C, Yuan Z, Liu Z and Li C (2019) Selectivity of Benzyl Hydroxamic Acid in the Flotation of IImenite. Front. Chem. 7:886. doi: 10.3389/fchem.2019.00886

\section{Selectivity of Benzyl Hydroxamic Acid in the Flotation of Ilmenite}

\author{
Lixia $L i^{1}$, Chen Zhang ${ }^{1 *}$, Zhitao Yuan ${ }^{1}$, Zhichao $L i u^{2}$ and Chunfeng $L i^{2}$ \\ ${ }^{1}$ School of Resources and Civil Engineering, Northeastern University, Shenyang, China, ${ }^{2}$ Beijing Research Institute of \\ Chemical Engineering and Metallurgy, CNNC, Beijing, China
}

The decreased ground size of ilmenite-bearing ores challenges the selectivity of collectors of ilmenite. Taking advantage of flotation tests and density functional theory (DFT), the selectivity of benzyl hydroxamic acid (BHA) and the adsorption mechanism of oleate and $\mathrm{BHA}$ on ilmenite were systematically investigated. The flotation tests showed that $\mathrm{BHA}$ had good selectivity to ilmenite. In the DFT study, the favorable adsorption of BHA and oleate on the ilmenite surface were verified by the Mulliken population and the calculated interaction energies. Results indicated that the covalent bonds caused the adsorption of oleate on the ilmenite surface. The strong selectivity of BHA was due to abundant adsorption sites and solid adsorption of five-membered rings. The present investigation has important implications for further studies of $\mathrm{BHA}$ and will be helpful for screening and designing collectors for ilmenite flotation.

Keywords: ilmenite, benzyl hydroxamic acid, selectivity, density functional theory, flotation

\section{INTRODUCTION}

For the beneficiation of ilmenite-bearing ores, a hybrid beneficiation method of low-intensity magnetic separation (LIMS) for magnetite removal and high-intensity magnetic separation (HIMS) for ilmenite pre-concentration followed by flotation for ilmenite upgrade, is commonly commercialized. With the continuous exploitation of ilmenite-bearing ores in China, the mined resources exhibit lean, fine, and miscellaneous. In order to liberate valuable minerals to a higher degree, fine grinding is applied, which is challenging the selectivity of collectors to ilmenite in the flotation section.

As an anionic collector, benzyl hydroxamic acid (BHA) has been increasingly brought attention to the field of mineral processing in the flotation of tungsten, iron, and rare earth minerals (Bulatovic and Wyslouzil, 1999) owing to its good selectivity. Investigations also showed that BHA as a collector can effectively separate ilmenite from associated gangue minerals, especially fine particles of ilmenite disseminated in the gangue minerals (Belardi et al., 1998; Li et al., 2016).

Many researchers have used hydroxamic acid as a collector to separate different minerals by flotation. Ren et al. (1997) used naphthyl hydroxamic acid for the flotation of bastnaesite. The flotation results showed that the naphthyl hydroxamic acid had good selectivity on the bastnaesite with regards to chemisorption. Sreenivas and Padmanabhan (2002) studied the floatability and adsorption characteristics of BHA on cassiterite. The results showed that the adsorption capacity of cassiterite for octyl hydroxamic acid was greatest under acidic conditions. The optimal slurry $\mathrm{pH}$ also changed greatly as the carbon chain of hydroxamic acid increased and the cassiterite particle size decreased. Beyond that, the cyclohexyl hydroxamic acid (Zhao et al., 2013) and octyl hydroxamic (Meng et al., 2015) were employed in the flotation of scheelite flotation and fine wolframite flotation. Novel carboxyl hydroxamic acids (Jiang et al., 2010) were also be designed 
and used for the flotation of aluminosilicate minerals. In the field of titanium minerals flotation, relevant studies have used hydroxamic acid as a collector (Buckley and Parker, 2013; Meng et al., 2015; Somasundaran, 2018; Chen et al., 2019). It can be seen that various forms of hydroxamic acid are attracting interest in mineral processing due to their unique properties.

During the flotation process, collectors can anchor on the mineral surface as a medium between mineral and air bubbles (Rao and Forssberg, 1991). In the present flotation of ilmenite ore, fatty acids and their modified products commonly serve as collectors industrially. BHA has been proving as a potential alternative to fatty acids due to its good selectivity to ilmenite (Bulatovic and Wyslouzil, 1999), and experiments demonstrate that the flotation performance of BHA is significantly better than that of oleate (shown in section Flotation Results). In view of this phenomenon, based on the mechanism of the collector, two hypotheses have been advanced: that BHA has more adsorption sites on ilmenite surfaces than that of oleate; and that the bond between BHA and the ilmenite surface is more solid than for oleate. Density functional theory (DFT) was applied to energy calculation and bond analysis to provide a quantitative comparison (Li et al., 2019).

DFT is able to reveal the reaction mechanisms that are difficult to explain by current experimental techniques at the atomic level (Pradip et al., 2002). It has been widely used (Kwon and Kubicki, 2004; Blanchard et al., 2012) to investigate properties of molecules and minerals surface as well as the interaction of adsorbent on the adsorbate. The properties of molecular, interaction energies, and Mulliken population analysis give a vivid characterization to the sorption mechanism and provide deep insight into the separation process from the aspects of physical and chemical (Rath et al., 2014). In our previous study, the mechanism of depression of hematite and the adsorption mechanism of oleate on siderite were investigated using DFT (Pradip et al., 2002; Li et al., 2018, 2019; Zhang et al., 2019, 2020).

The aim of this paper was to identify the adsorption configuration of BHA and oleate on the surface of ilmenite, using flotation tests to testify the selectivity of oleate and BHA, and applying DFT to demonstrate the adsorption mechanism. First, flotation tests were conducted at optimal conditions for BHA and sodium oleate, respectively, and the grade and recovery of ilmenite concentrate were compared. Second, the exposed surface of the ilmenite crystal was determined based on the calculation of surface energy. Finally, different models of oleate and BHA were built and screened. The models with the lowest adsorption energy were calculated to analyze the mechanism of adsorption.

\section{MATERIALS AND METHODOLOGY \\ Experimental Materials}

The fine ilmenite sample involved in this study was a classifier overflow materials in a titanium beneficiation plant of Panzhihua Iron \& Steel Group Co. in China, with a particle size of $-0.038 \mathrm{~mm}$ passing $86.18 \%$ and $\mathrm{TiO}_{2}$ grade of $8.89 \%$. After treated by a LIMS and a superconducting magnetic separator, it was upgraded to $17.01 \%$ of $\mathrm{TiO}_{2}$. This concentrate was collected, dried, homogenized, and sampled to perform flotation experiments.

$\mathrm{BHA}$ and sodium oleate were used as collectors. In order to prepare the solution of sodium oleate, $50 \mathrm{mg}$ of sodium oleate was put into a $500 \mathrm{~mL}$ beaker placed in an ultrasonic dispersion machine. Then the dispersed solution was transferred into a $1 \mathrm{~L}$ volumetric flask with deionized water to a final concentration of $50 \mathrm{mg} / \mathrm{L}$. The same procedure was followed to prepare a BHA solution with a concentration of $50 \mathrm{mg} / \mathrm{L}$. All experiments were carried out at room temperature. Lead nitrate $\mathrm{Pb}\left(\mathrm{NO}_{3}\right)_{2}$ had an analytical purity and was adopted as an activator, and the frother terpenic oil was commercially pure.

\section{Flotation Experiments}

An XFG flotation machine with $1 \mathrm{~L}$ flotation cell was used for the flotation experiments with a stirring rate of 1,800 rpm. With BHA and sodium oleate as a collector separately, experimental optimizations with parameters of slurry $\mathrm{pH}$, dosages of reagents, and flotation time, have been implemented. In each experiment, $300 \mathrm{~g}$ of samples were added in $700 \mathrm{~mL}$ of water to stir for $3 \mathrm{~min}$. Sulfuric acid $\left(\mathrm{H}_{2} \mathrm{SO}_{4}\right)$ or hydroxide sodium $(\mathrm{NaOH})$ was employed to adjust slurry $\mathrm{pH}$ from 4 to 12 .

In the case of BHA, after $\mathrm{pH}$ adjustment, activator, collector, and frother were added in sequence and conditioned for 3, 5, and 1 min correspondingly. After that, the flotation test was carried out, and the froth was scrapped off every $10 \mathrm{~s}$. While in the case of sodium oleate, collector, and frother were added into the slurry after $\mathrm{pH}$ adjustment at the same time intervals to those of BHA. When flotation completed, both floated and sunk fractions were dried in an oven at $60^{\circ} \mathrm{C}$, and then weighed and chemically analyzed.

As a result, suitable flotation conditions with BHA for ilmenite were determined as $\mathrm{pH}$ of $7.0, \mathrm{PbNO}_{3}$ of $200 \mathrm{~g} / \mathrm{t}, \mathrm{BHA}$ of $1,300 \mathrm{~g} / \mathrm{t}$, frother of $60 \mathrm{~g} / \mathrm{t}$ and flotation time of $5 \mathrm{~min}$. While for sodium oleate, optimized flotation conditions were $\mathrm{pH}$ of 4.5 , sodium oleate of 1,500g/t, $40 \mathrm{~g} / \mathrm{t}$ of frother and flotation time of $5 \mathrm{~min}$.

\section{Models for IImenite Crystal}

The crystal optimization convergence tests of exchangecorrelation potentials, k-point, and cutoff energy were carried out to get the optimum ilmenite crystal geometry. The exchangecorrelation potentials of generalized gradient approximation (GGA) convergence test included GGA-RPBE, GGA-WC, GGAPBE, GGA-PBESOL, and GGA-PW91. The convergence criteria of max. displacement $=0.002 \AA$, energy $=2.0 \times 10^{-5} \mathrm{eV}$, $\max$. stress $=0.1 \mathrm{GPa}$, and $\max$. force $=0.05 \mathrm{eV} / \AA$. The lattice parameters of ilmenite from the literature and experimental values were referred to ensure the suitability of optimized ilmenite crystal (Wechsler and Prewitt, 1984). In this study, the CASTEP module in Materials Studio was employed for all calculations.

Based on the results of these convergence tests, the cutoff energy of $300 \mathrm{eV}$, exchange-correlation potential of GGA-PW91 and k-point set $6 \times 6 \times 2$ were selected with the energy $-22717.6637 \mathrm{eV}$ and the parameter difference $1.4 \%$, which confirmed the suitability of parameter selection for accurate calculations. Figure 1 shows the optimum ilmenite crystal. 


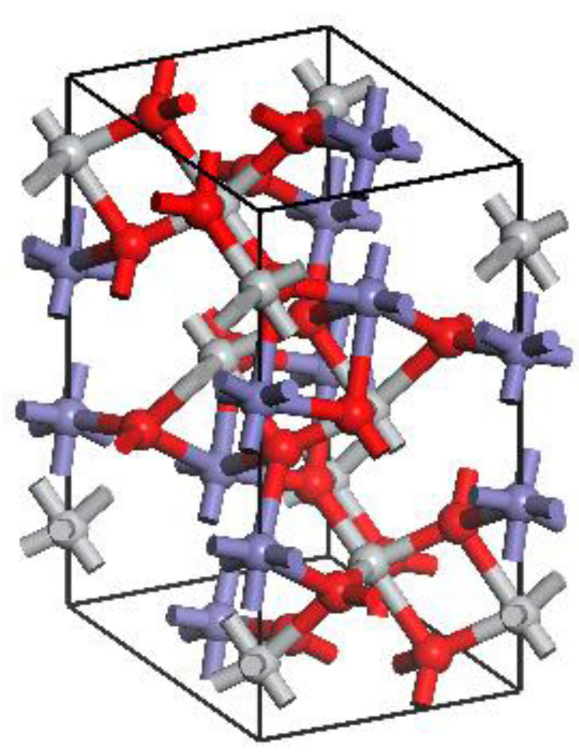

FIGURE 1 | Optimum ilmenite crystal. The red spheres represent $O$ atoms, the gray represents $\mathrm{Ti}$ atoms, and the blue represents Fe atoms.

\section{Models for the Ilmenite Surface}

To get the most likely exposed crystal surface of ilmenite, the surface energy calculation was conducted. Surface energy was a thermodynamic stability measurement of an exposed crystalline surface. The smaller surface energy corresponds to a more stable surface structure (Lavina et al., 2009). In this study, the Equation (1) was used to calculate the surface energy (Hu et al., 2012).

$$
E_{\text {surf }}=\frac{E_{\text {slab }}-\left(\frac{N_{\text {slab }}}{N_{\text {bulk }}}\right) \cdot E_{\text {bulk }}}{2 \mathrm{~A}}
$$

where $E_{\text {bulk }}$ and $E_{\text {slab }}$ are the bulk unit cell and the total energy of the slab, respectively; $N_{b u l k}$ is the number contained in each bulk unit cell and $N_{\text {slab }}$ is the number of atoms in ilmenite slab; unit area of the surface was represented by $A$ and the factor of 2 represents the two surfaces in the surface slab that are perpendicular to the $\mathrm{z}$-axis.

In this study, the ilmenite crystal surfaces ( $\left.\begin{array}{lll}1 & 0 & 4\end{array}\right),\left(\begin{array}{lll}1 & 1 & 0\end{array}\right),\left(\begin{array}{ll}1 & 1\end{array}\right.$ -6), ( $\left.\begin{array}{lll}0 & 1 & 2\end{array}\right),\left(\begin{array}{ll}0 & 2\end{array}\right)$, and ( 300 ) were selected for comparison with the most readily existing crystal surfaces, according to the XRD results. The selected crystal surface was then used to establish the model of ilmenite with reagents.

\section{Models of Reagents}

The representative of modeled conditions to experimental flotation conditions has been considered. Slurry $\mathrm{pH}$ determines the predominant functional groups of reagents. As abovementioned, with sodium oleate as a collector, the optimized flotation $\mathrm{pH}$ for ilmenite samples was 4.5 , while for BHA it was 7.0. Well-known that the predominant group for sodium oleate at $\mathrm{pH}$ of 4.5 is oleate molecule, for BHA and $\mathrm{Pb}\left(\mathrm{NO}_{3}\right)_{2}$ at $\mathrm{pH}$ of 7.0 , BHA molecule and $\mathrm{Pb}(\mathrm{OH})^{+}$are dominant species.
TABLE 1 | Flotation results of $\mathrm{BHA}$ and oleate.

\begin{tabular}{llrcc}
\hline Collector & Product & Yield/\% & TiO $_{2}$ grade/\% & TiO $_{2}$ recovery/\% \\
\hline \multirow{2}{*}{ BHA } & Concentrate & 16.38 & 39.25 & 37.79 \\
& Tailings & 83.62 & 12.65 & 62.21 \\
& Feed & 100.00 & 17.01 & 100.00 \\
\multirow{2}{*}{ Oleate } & Concentrate & 32.95 & 28.42 & 55.06 \\
& Tailings & 67.05 & 11.40 & 44.94 \\
& Feed & 100.00 & 17.01 & 100.00 \\
\hline
\end{tabular}

TABLE 2 | Surface energies of different ilmenite surfaces.

\begin{tabular}{lcccc}
\hline Crystal surface & $\boldsymbol{E}_{\text {bulk }} / \mathbf{e V}$ & $\boldsymbol{E}_{\text {slab }} / \mathbf{e V}$ & $\boldsymbol{A} / \AA^{2}$ & $\boldsymbol{E}_{\text {surf }} / \mathbf{J}^{\mathbf{m}} \mathbf{m}^{\mathbf{2}}$ \\
\hline$\left(\begin{array}{lllll}1 & 0 & 4\end{array}\right)$ & -22717.650 & -22711.667 & 94.25 & 0.509 \\
$\left(\begin{array}{lll}1 & 1 & 0\end{array}\right)$ & -22717.650 & -22704.376 & 92.57 & 1.149 \\
\hline
\end{tabular}

In this study, the surface of ilmenite was the adsorbent and the $\mathrm{BHA}$, oleate, and $\mathrm{Pb}(\mathrm{OH})^{+}$were adsorbates. The Visualizer module was employed to design the oleate, $\mathrm{BHA}$ and $\mathrm{Pb}(\mathrm{OH})^{+}$ molecular structures. Before adsorption modeling, geometric optimizations of the oleate, $\mathrm{BHA}$ and $\mathrm{Pb}(\mathrm{OH})^{+}$molecular structures were conducted using the CASTEP module.

\section{RESULTS AND DISCUSSION}

\section{Flotation Results}

Using BHA and oleate as collectors, flotation tests were performed at their optimal conditions. Flotation performances in terms of grade and recovery of ilmenite are presented in Table 1.

As can be seen from Table 1, BHA enriched the $\mathrm{TiO}_{2}$ grade from $17.01 \%$ of the feed to $39.25 \%$ of the concentrate which was higher than $28.42 \%$ obtained with oleate. In contrast, BHA displayed relatively poor floatability for ilmenite, i.e., with oleate as collector the recovery of $\mathrm{TiO}_{2}$ in concentrate was $55.06 \%$, which was higher than that of $37.79 \%$ with BHA. The results show that BHA has good selectivity to ilmenite and oleate has good floatability to ilmenite.

\section{Selected IImenite Surfaces}

The dominant crystal face of ilmenite was determined by surface energy. The crystal morphology is dominated by the crystal surfaces with a slow-growing rate, meanwhile, a slower growth rate means that a surface has lower surface energy, while fastgrowing faces with higher surface energy may disappear (Prywer, 2001). Ilmenite surfaces (1 04 ), (l $\left.\begin{array}{lll}1 & 1 & 0\end{array}\right),\left(\begin{array}{lll}1 & 1 & -6\end{array}\right),\left(\begin{array}{lll}0 & 1 & 2\end{array}\right),\left(\begin{array}{ll}0 & 2\end{array}\right.$ $4)$, and $\left(\begin{array}{lll}3 & 0 & 0\end{array}\right)$ were modeled as a six-layer slab with a vacuum thickness of $25 \AA$, and the most stable crystal surfaces were determined based on the calculated surface energies as shown in Table 2.

The calculation process for surfaces $\left(\begin{array}{lll}1 & 1 & -6\end{array}\right),\left(\begin{array}{lll}0 & 1 & 2\end{array}\right),\left(\begin{array}{lll}0 & 2 & 4\end{array}\right)$, and $\left(\begin{array}{lll}3 & 0 & 0\end{array}\right)$ did not converge, which indicated that the types of atom exposed on the crystal surfaces were unlikely to exist, while the surfaces ( $\left.\begin{array}{lll}1 & 0 & 4\end{array}\right)$ with surface energy of $0.509 \mathrm{~J} \cdot \mathrm{m}^{-2}$ and $\left(\begin{array}{lll}1 & 1 & 0\end{array}\right)$ with $1.149 \mathrm{~J} \cdot \mathrm{m}^{-2}$ converged to a stable surface slab. The surface 


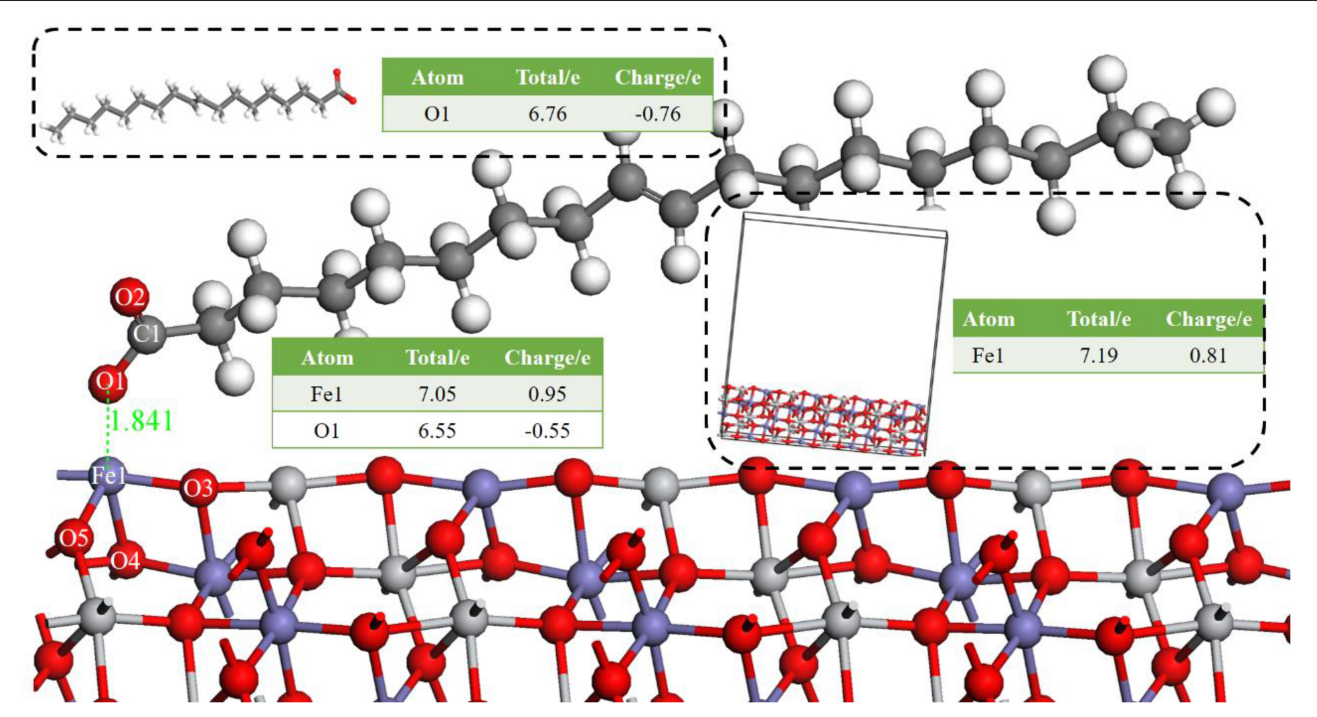

FIGURE 2 | The optimal bond of oleate on an ilmenite $\left(\begin{array}{lll}1 & 0 & 4\end{array}\right)$ surface, the red ball is $\mathrm{O}$, the blue ball is Fe, the light gray ball is Ti, the dark gray ball is $\mathrm{C}$, and the white ball is $\mathrm{H}$.

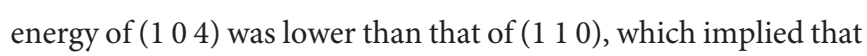
the surface ( $\left(\begin{array}{lll}1 & 0 & 4\end{array}\right)$ would more likely exist. Therefore, the surface (1 04 ) was adopted in the subsequent calculations to establish the mineral-reagent models.

\section{Models for Mineral-Reagent Complex}

Models of oleate and BHA on ilmenite surface were built and calculated to reveal the greater selectivity of BHA as compared with oleate. Bond strength was revealed by the adsorption energy and Mulliken bonds population. The adsorption energy $\left(\Delta E_{a d s}\right)$ of reagents and optimized ilmenite $\left(\begin{array}{lll}1 & 0 & 4\end{array}\right)$ were quantified by Equation (2) (Hu et al., 2012):

$$
\Delta E_{\text {ads }}=E_{\text {complex }}-\left(E_{\text {adsorbate }}+E_{\text {mineral }}\right)
$$

where $E_{\text {complex }}$ is the energy of optimized ilmenite-reagent complex, $E_{\text {adsorbate }}$ refers to the total energy of the reagents and $E_{\text {mineral }}$ is the total energy of the ilmenite crystal surface. A greater (negative) magnitude of $\Delta E$ implies a stronger interaction between the mineral surface and reagent.

Mulliken population analysis was conducted to specify the bond types between adsorbent and adsorbate. The Mulliken bond population is positive for a covalent bond, and the covalent bonding becomes stronger with the increase of Mulliken population. Similarly, a negative bond population indicates antibond.

\section{Models for IImenite-Oleate Complex}

Figure 2 shows the apparent interaction of oleate with the atoms on ilmenite surface. The adsorption energy (Equation 2) of oleate on the surface of ilmenite was $-146.501 \mathrm{~kJ} / \mathrm{mol}$, which demonstrated that the oleate adsorbed on the ilmenite surface with a distance of $1.841 \AA$ between the Fe1 and $\mathrm{O} 1$ atoms. Mulliken population analysis was conducted to discern the bond type of oleate on ilmenite. The bond populations are listed in Table 3.
TABLE 3 | Mulliken population of adsorption configuration of oleate on ilmenite.

\begin{tabular}{lccc}
\hline Atom & Bond & Bond population & Bond length/ \\
\hline Fe1 & O1-Fe1 & 0.42 & 1.840 \\
& O5-Fe1 & 0.25 & 1.880 \\
& O3-Fe1 & 0.31 & 1.893 \\
O1 & O3-O1 & -0.01 & 2.830 \\
& C1-O1 & 0.74 & 1.340 \\
\hline
\end{tabular}

As shown in Table 3, the bond population of O1-Fe1 was 0.42 , indicating that a covalent bond was generated between the Fe1 on the ilmenite surface and $\mathrm{O} 1$ of oleate. The bond population of $\mathrm{O} 1-\mathrm{Fe} 1$ was lower than that of $\mathrm{C} 1-\mathrm{O} 1$ in oleate $(0.74)$, yet higher than O5-Fe1 (0.25) and O3-Fe1 (0.31) in the ilmenite crystal, indicating that the interaction between the atoms of $\mathrm{Fe}$ and $\mathrm{O}$ was strong enough to trigger the adsorption of oleate on the ilmenite surface. The atom population in Figure 2 demonstrates that the charge of $\mathrm{O} 1$ and $\mathrm{Fe} 1$ are -0.76 e and 0.81 e before the adsorption of oleate on ilmenite surface. After a series reaction, the oleate absorbed on the surface of ilmenite. The total charge of O1 changed from -0.76 e to -0.55 e with 0.21 e lose of charge. Meanwhile, the charge of Fe1 went from 0.81 e to $0.95 \mathrm{e}$, which manifests the electron transfer existed between $\mathrm{O} 1$ and Fel atom, which contributed to the formation of covalent bonds.

\section{Models for Ilmenite- $\mathrm{Pb}(\mathrm{OH})^{+}-\mathrm{BHA}$ Complex}

In the flotation of ilmenite with BHA, the activator lead nitrate is usually added before the collector BHA. Therefore, the adsorption of $\mathrm{Pb}(\mathrm{OH})^{+}$on the ilmenite surface was calculated first. The different models of $\mathrm{Pb}(\mathrm{OH})^{+}$are shown in Figure 3.

During building the models of $\mathrm{Pb}(\mathrm{OH})^{+}$on the ilmenite surface, $\mathrm{Pb}(\mathrm{OH})^{+}$was placed on the top of $\mathrm{Fe}, \mathrm{Ti}$, and $\mathrm{O}$ atoms of the ilmenite surface to find the best adsorption site. The adsorption energy of $\mathrm{Pb}(\mathrm{OH})^{+}$on the ilmenite surface was 


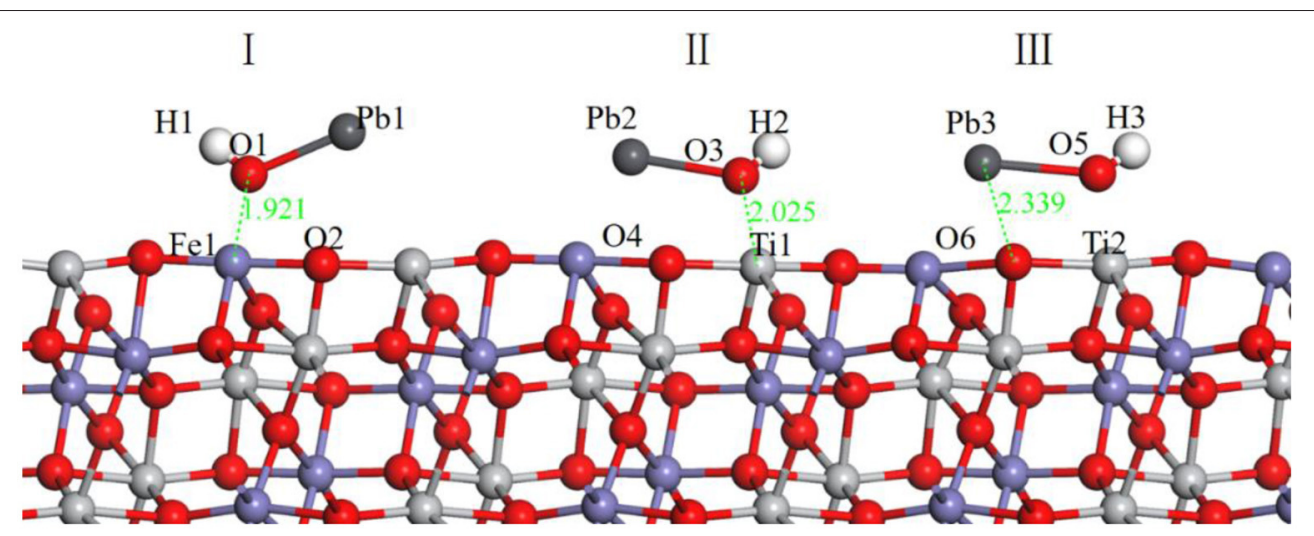

FIGURE 3 | Models of $\mathrm{Pb}(\mathrm{OH})^{+}$on ilmenite surface, (I) represents the $\mathrm{Pb}(\mathrm{OH})^{+}$on the top of Fe atom, (II) represents the $\mathrm{Pb}(\mathrm{OH})^{+}$on the top of Ti atom, (III) represents the $\mathrm{Pb}(\mathrm{OH})^{+}$on the top of $\mathrm{O}$ atom. The black ball is $\mathrm{Pb}$.

TABLE 4 | Mulliken population of adsorption configuration of $\mathrm{Pb}(\mathrm{OH})^{+}$on the ilmenite surface.

\begin{tabular}{|c|c|c|c|}
\hline $\mathrm{Pb}(\mathrm{OH})^{+}$ & Bond & Bond population & Bond length/Å \\
\hline \multirow[t]{2}{*}{ I } & Fe1-O1 & 0.22 & 1.921 \\
\hline & O1-O2 & -0.06 & 2.520 \\
\hline \multirow[t]{2}{*}{$\|$} & Ti1-O3 & 0.31 & 2.025 \\
\hline & O3-O4 & -0.05 & 2.593 \\
\hline \multirow[t]{2}{*}{ III } & Ti2-O5 & 0.22 & 2.000 \\
\hline & O6-O5 & -0.04 & 2.686 \\
\hline
\end{tabular}

TABLE 5 | Atom population of $\mathrm{Pb}(\mathrm{OH})^{+}$on the ilmenite surface.

\begin{tabular}{llcr}
\hline Atom & Status & Total/e & Charge/e \\
\hline Fe1 & Before adsorption & 7.19 & 0.81 \\
& After adsorption & 7.05 & 0.95 \\
01 & Before adsorption & 6.66 & -0.66 \\
& After adsorption & 6.58 & -0.58
\end{tabular}

calculated as $-16.916 \mathrm{~kJ} / \mathrm{mol}$. Figure 3 shows that all of the $\mathrm{Pb}(\mathrm{OH})^{+}$was adsorbed on the ilmenite surface. Table 4 shows the bond population of $\mathrm{Pb}(\mathrm{OH})^{+}$.

As shown in Table 4, the atoms of Fe and $\mathrm{Ti}$ on the ilmenite surface interacted with $\mathrm{O}$ of $\mathrm{Pb}(\mathrm{OH})^{+}$with bond populations of $0.22,0.31$, and 0.22 , respectively. This confirmed that the $\mathrm{Pb}(\mathrm{OH})^{+}$adsorbed on the ilmenite surface by covalent bonding, and that adsorption sites were abundant.

Table 5 exhibits the atom population of $\mathrm{Fe} 1$ and $\mathrm{O} 1$ before and after the adsorption of $\mathrm{Pb}(\mathrm{OH})^{+}$.

Known from Table 5, both $\mathrm{Fe} 1$ and $\mathrm{O} 1$ atoms have obvious electron transfer during the reaction, and $0.14 \mathrm{e}$ and $0.08 \mathrm{e}$ removed from $\mathrm{Fe} 1$ and $\mathrm{O} 1$ atom, respectively, which supplement the interaction between $\mathrm{O}$ in $\mathrm{Pb}(\mathrm{OH})^{+}$and $\mathrm{Fe}$ in the ilmenite surface.

Having identified the adsorption of $\mathrm{Pb}(\mathrm{OH})^{+}$, the interaction between $\mathrm{BHA}$ and the ilmenite surface $\mathrm{Pb}(\mathrm{OH})^{+}$-functioned was calculated to detect the selectivity of BHA. The optimized model is shown in Figure 4.

As shown in Figure 4, BHA adsorbed on ilmenite surface via the interaction between the $\mathrm{Pb}$ atom of $\mathrm{Pb}(\mathrm{OH})^{+}$and the $\mathrm{O}$ atom of $\mathrm{BHA} . \mathrm{Pb}^{2+}$ and the $\mathrm{O}$ atoms formed a five-membered ring, and this interaction was stronger than that of oleate with ilmenite. The adsorption energy was determined as $-101.1528 \mathrm{~kJ} / \mathrm{mol}$ and the bond population analysis indicated that the BHA adsorbed on the three sites of the ilmenite surface. The five-membered ring and the abundant adsorption sites lead to the good selectivity of $\mathrm{BHA}$. From the atom population analysis, the charge of $\mathrm{Pb} 1$ went from 0.29 to 1.08 , and the two $\mathrm{O}$ of $\mathrm{BHA}$ also had obvious charge transfer which confirmed the interaction among the two $\mathrm{O}$ of $\mathrm{BHA}$ and $\mathrm{Pb}$ of activated ilmenite surface.

Based on the results and discussion, both oleate and BHA could adsorb on the ilmenite surface. Covalent bonds formed between $\mathrm{Fe}$ of ilmenite surface and the $\mathrm{O}$ of oleate. Due to the activation of $\mathrm{Pb}(\mathrm{OH})^{+}$, there were more adsorption sites of ilmenite for BHA (Meng et al., 2018; Ozsváth et al., 2019). And five-membered rings formed among lead species and BHA, which improved the selectivity of BHA.

\section{CONCLUSION}

This study highlighted the good selectivity of BHA for ilmenite. Flotation tests were performed to discover the difference in selectivity between BHA and oleate, and the DFT calculation of the reagent-ilmenite complexes was adopted to elucidate the mechanism of the good selectivity of BHA at the atomic level.

Flotation tests showed that the selectivity of BHA was better than that of oleate. DFT calculation suggested that both oleate and BHA adsorbed on the ilmenite surface. BHA had more adsorption sites on ilmenite surfaces, as it formed fivemembered rings through the $\mathrm{O}$ atoms of $\mathrm{BHA}$ and $\mathrm{Pb}^{2+}$ of the activator. Abundant adsorption sites and solid adsorption of five-membered rings contribute to the good selectivity of BHA. 


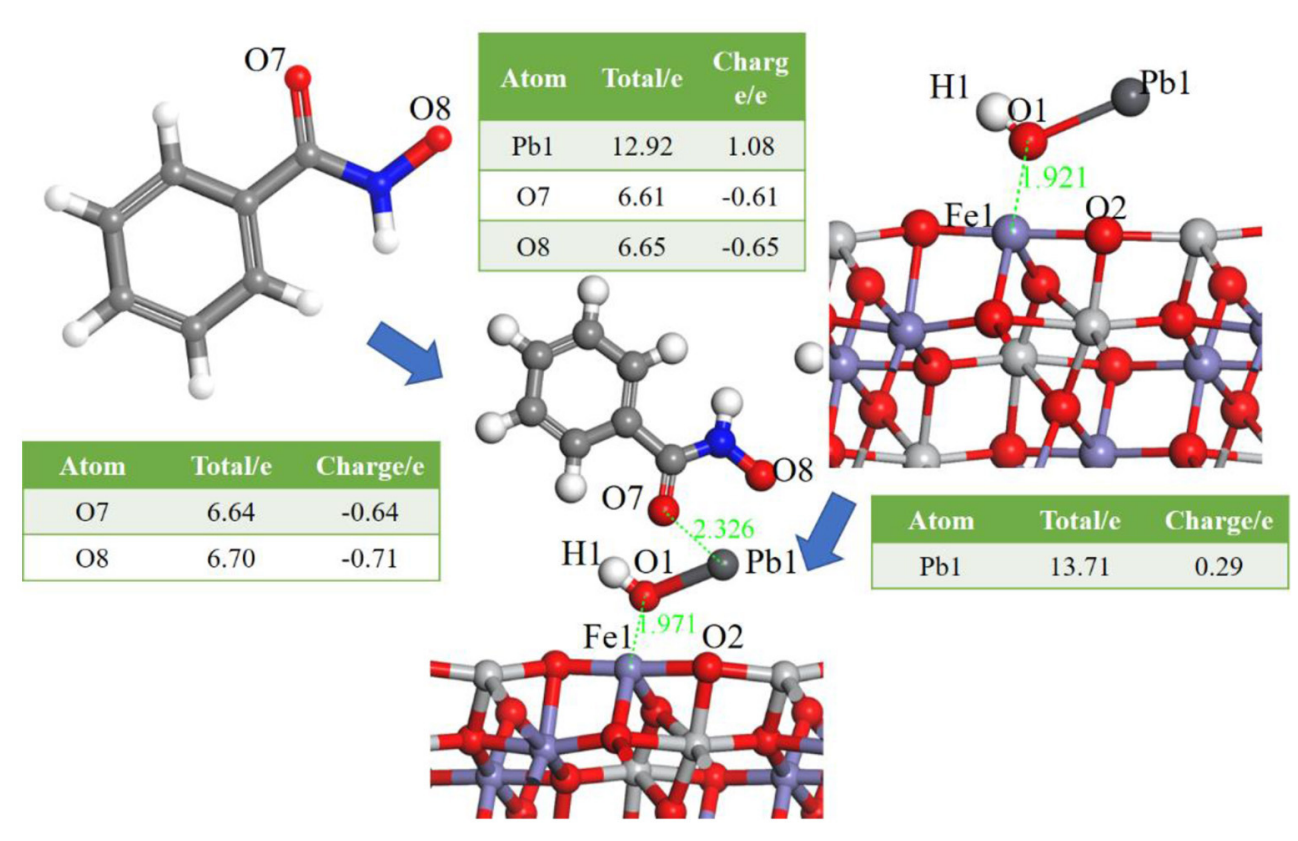

FIGURE 4 | Models of $\mathrm{BHA}$ on the $\mathrm{Pb}(\mathrm{OH})^{+}$-functioned ilmenite surface, the Table is the atom population before and after the adsorption of $\mathrm{BHA}$.

The present investigation offers insight into the good selectivity of BHA, providing a reference for designing and screening flotation reagents for ilmenite flotation.

\section{DATA AVAILABILITY STATEMENT}

The datasets generated for this study are available on request to the corresponding author.

\section{AUTHOR CONTRIBUTIONS}

During investigation and paper writing, all authors participated in their assigned tasks. LL carried out flotation experiments, drafted the flotation tests, and analyzed DFT calculation results with $\mathrm{CZ}$, who performed the DFT calculation and wrote the paragraphs of DFT calculation. ZY was responsible for designing

\section{REFERENCES}

Belardi, G., Piga, L., Quaresima, S., and Shehu, N. (1998). Application of physical separation methods for the upgrading of titanium dioxide contained in a fine waste. Int. J. Miner. Process. 53, 145-156. doi: 10.1016/S0301-7516(97)0 0076-8

Blanchard, M., Morin, G., Lazzeri, M., Balan, E., and Dabo, I. (2012). Firstprinciples simulation of arsenate adsorption on the (1 12 2) surface of hematite. Geochim. Cosmochim. Acta 86, 182-195. doi: 10.1016/j.gca.2012.03.013

Buckley, A. N., and Parker, G. K. (2013). Adsorption of n-octanohydroxamate collector on iron oxides. Int. J. Miner. Process. 121, 70-89. doi: 10.1016/j.minpro.2013.03.004

Bulatovic, S., and Wyslouzil, D. (1999). Process development for treatment of complex perovskite, ilmenite and rutile ores. Miner. Eng. 12, 1407-1417. doi: 10.1016/S0892-6875(99)00130-2 the experimental scheme and outlining the manuscript structure. ZL and CL repeated flotation tests using BHA and contributed to the interpretations of flotation results and the revision of whole manuscript.

\section{FUNDING}

This study was supported by the National Natural Science Foundation of China (No. 51574061), the Fundamental Research Funds for the Central Universities (N180106005), and the Open Foundation of State Key Laboratory of Mineral Processing (No. BGRIMM-KJSKL-2019-01).

\section{ACKNOWLEDGMENTS}

We would like to express our gratitude to editors and reviewers for their diligent work.

Chen, W., Chen, F. F., Bu, X. Z., Zhang, G. F., Zhang, C. H., and Song, Y. H. (2019). A significant improvement of fine scheelite flotation through rheological control of flotation pulp by using garnet. Miner. Eng. 138, 257-266. doi: 10.1016/j.mineng.2019.05001

Hu, Y., Gao, Z., Sun, W., and Liu, X. (2012). Anisotropic surface energies and adsorption behaviors of scheelite crystal. Colloids Surf. A Physicochem. Eng. Aspects 415, 439-448. doi: 10.1016/j.colsurfa.2012.09.038

Jiang, Y.-R., Zhao, B.-N., Zhou, X.-H., and Zhou, L.-Y. (2010). Flotation of diaspore and aluminosilicate minerals applying novel carboxyl hydroxamic acids as collector. Hydrometallurgy 104, 112-118. doi: 10.1016/j.hydromet.2010.05.006

Kwon, K. D., and Kubicki, J. D. (2004). Molecular orbital theory study on surface complex structures of phosphates to iron hydroxides: calculation of vibrational frequencies and adsorption energies. Langmuir 20, 9249-9254. doi: $10.1021 / \mathrm{la} 0487444$ 
Lavina, B., Dera, P., Downs, R. T., Prakapenka, V., Rivers, M., Sutton, S., et al. (2009). Siderite at lower mantle conditions and the effects of the pressure-induced spin-pairing transition. Geophys. Res. Lett. 36. doi: 10.1029/2009GL039652

Li, F., Zhong, H., Zhao, G., Wang, S., and Liu, G. (2016). Adsorption of $\alpha$-hydroxyoctyl phosphonic acid to ilmenite/water interface and its application in flotation. Colloids Surf. A Physicochem. Eng. Aspects 490, 67-73. doi: 10.1016/j.colsurfa.2015.11.015

Li, L., Zhang, C., Yuan, Z., Hao, H., and Zhao, C. (2018). Density functional theory and atomic force microscopy study of oleate functioned on siderite surface. Minerals. 8:33. doi: 10.3390/min 8010033

Li, L., Zhang, C., Yuan, Z., Xu, X., and Song, Z. (2019). AFM and DFT study of depression of hematite in oleate-starch-hematite flotation system. Appl. Surf. Sci. 480, 749-758. doi: 10.1016/j.apsusc.2019.02.224

Meng, Q., Feng, Q., Shi, Q., and Ou, L. (2015). Studies on interaction mechanism of fine wolframite with octyl hydroxamic acid. Miner. Eng. 79, 133-138. doi: 10.1016/j.mineng.2015.05.015

Meng, Q., Yuan, Z., Yu, L., Xu, Y., and Du, Y. (2018). Study on the activation mechanism of lead ions in the flotation of ilmenite using benzyl hydroxamic acid as collector. J. Indus. Eng. Chem. 62, 209-216. doi: 10.1016/j.jiec.2017.12.059

Ozsváth, A., Farkas, E., Diószegi, R., and Buglyó, P. (2019). Versatility and trends in the interaction between $\mathrm{Pd}$ (ii) and peptide hydroxamic acids. N. J. Chem. 43, 8239-8249. doi: 10.1039/C9NJ00296K

Pradip, P., Rai, B., Rao, T., Krishnamurthy, S., Vetrivel, R., Mielczarski, J., et al. (2002). Molecular modeling of interactions of diphosphonic acid based surfactants with calcium minerals. Langmuir 18, 932-940. doi: $10.1021 / \mathrm{la} 010625 \mathrm{q}$

Prywer, J. (2001). Effect of crystal geometry on disappearance of slow-growing faces. J. Cryst. Growth 224, 134-144. doi: 10.1016/S0022-0248(01)00798-9

Rao, K. H., and Forssberg, K. (1991). Mechanism of fatty acid adsorption in salt-type mineral flotation. Miner. Eng. 4, 879-890. doi: 10.1016/0892-6875(91)90071-3

Rath, S. S., Sinha, N., Sahoo, H., Das, B., and Mishra, B. K. (2014). Molecular modeling studies of oleate adsorption on iron oxides. Appl. Surf. Sci. 295, 115-122. doi: 10.1016/j.apsusc.2014.01.014
Ren, J., Lu, S., Song, S., and Niu, J. (1997). A new collector for rare earth mineral flotation. Miner. Eng. 10, 1395-1404. doi: 10.1016/S0892-6875(97)0 0129-5

Somasundaran, P. (2018). Reagents in Mineral Technology. Routledge.

Sreenivas, T., and Padmanabhan, N. (2002). Surface chemistry and flotation of cassiterite with alkyl hydroxamates. Colloids Surf. A Physicochem. Eng. Aspects 205, 47-59. doi: 10.1016/S0927-7757(01)01146-3

Wechsler, B. A., and Prewitt, C. T. (1984). Crystal structure of ilmenite (FeTiO3) at high temperature and at high pressure. Am. Mineral. 69, 176-185.

Zhang, C., Li, L., Yuan, Z., Xu, X., Song, Z., and Zhang, Y. (2019). Probing the effect of particle imperfections on the sliming of siderite in carbonatebearing iron ore. Miner. Eng. 143:106014. doi: 10.1016/j.mineng.2019.1 06014

Zhang, C., Li, L., Yuan, Z., Xu, X., Song, Z., and Zhang, Y. (2020). Mechanical properties of siderite and hematite from DFT calculation. Miner. Eng. 146:106107. doi: 10.1016/j.mineng.2019.106107

Zhao, G., Zhong, H., Qiu, X., Wang, S., Gao, Y., Dai, Z., et al. (2013). The DFT study of cyclohexyl hydroxamic acid as a collector in scheelite flotation. Miner. Eng. 49, 54-60. doi: 10.1016/j.mineng.2013. 04.025

Conflict of Interest: ZL and CL are employed by Beijing Research Institute of Chemicals Engineering and Metallurgy, CNNC.

The remaining authors declare that the research was conducted in the absence of any commercial or financial relationships that could be construed as a potential conflict of interest.

Copyright (c) $2019 \mathrm{Li}$, Zhang, Yuan, Liu and Li. This is an open-access article distributed under the terms of the Creative Commons Attribution License (CC BY). The use, distribution or reproduction in other forums is permitted, provided the original author(s) and the copyright owner(s) are credited and that the original publication in this journal is cited, in accordance with accepted academic practice. No use, distribution or reproduction is permitted which does not comply with these terms. 